\title{
Characteristics and ecological risk assessment of polycyclic aromatic hydrocarbons in soil seepage water in karst terrains, southwest China
}

Article

Accepted Version

Creative Commons: Attribution-Noncommercial-No Derivative Works 4.0

Sun, Y., Zhang, S., Xie, Z., Lan, J., Li, T., Yuan, D., Yang, H. and Xing, B. (2020) Characteristics and ecological risk assessment of polycyclic aromatic hydrocarbons in soil seepage water in karst terrains, southwest China.

Ecotoxicology and Environmental Safety, 190. 110122. ISSN 0147-6513 doi: https://doi.org/10.1016/j.ecoenv.2019.110122 Available at https://centaur.reading.ac.uk/88507/

It is advisable to refer to the publisher's version if you intend to cite from the work. See Guidance on citing.

To link to this article DOI: http://dx.doi.org/10.1016/j.ecoenv.2019.110122

Publisher: Elsevier

All outputs in CentAUR are protected by Intellectual Property Rights law, including copyright law. Copyright and IPR is retained by the creators or other copyright holders. Terms and conditions for use of this material are defined in the End User Agreement. 


\section{www.reading.ac.uk/centaur}

\section{CentAUR}

Central Archive at the University of Reading

Reading's research outputs online 


\section{Characteristics and Ecological Risk Assessment of Polycyclic Aromatic}

\section{Hydrocarbons in Soil Seepage Water in Karst Terrains, Southwest China}

3 Yuchuan Sun ${ }^{\mathrm{a}, \mathrm{b}, \mathrm{c}^{*}}$, Siyu Zhang, ${ }^{\mathrm{c}, \mathrm{d}}$, Zhenglan Xie ${ }^{\mathrm{a}}$, Jiacheng Lan ${ }^{\mathrm{e}}$, Tian $\mathrm{Li}^{\mathrm{f}}$, Daoxian

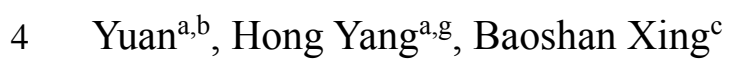

5 a Chongqing Key Laboratory of Karst Environment; School of Geographical Sciences;

$6 \quad$ Southwest University, Chongqing 400715, China

$7 \quad{ }^{b}$ Karst Dynamics Laboratory, Ministry of Land and Resources, Institute of Karst

8 Geology, Guilin 541004, China

9 c Stockbridge School of Agriculture, University of Massachusetts, Amherst,

$10 \quad$ Massachusetts 01003, United States

$1{ }^{d}$ Key Laboratory of Pollution Ecology and Environmental Engineering, Institute of

12 Applied Ecology Chinese Academy of Sciences, Shenyang 110016, China

13 e School of Karst Science, Guizhou Normal University/State Engineering Technology

14 Institute for Karst Desertification Control, Guiyang 550001, China

$15 f$ College of Plant Protection, Southwest University, Chongqing 400715, China

$16 \mathrm{~g}$ Department of Geography and Environmental Science, University of Reading,

17 Whiteknights, Reading, RG6 6AB, UK 
Abstract:

(

(in

investigate the ecological risks and factors controlling the subsurface transport of PAHs

in karst terrain in southwest China. The concentrations of dissolved PAHs in soil seepage water increased with depth and the mean concentrations at a depth of $80 \mathrm{~cm}$ were relatively high (exceeding $1147 \mathrm{ng} / \mathrm{L}$ ). PAH composition in soil seepage water was dominated by low molecular weight (LMW) PAHs, whereas those associated with soil matrix were dominated by high molecular weight (HMW) PAHs. The results revealed that HMW PAHs in soil seepage water were closer to the equilibrium of dissolution than LMW and medium molecular weight (MMW) PAHs. However, due to the carrier functions of dissolved organic matter (DOM) for HMW PAHs, all PAHs can be continuously dissolved in the soil seepage water from soil matrix as the water moved vertical downward through the profiles. During this process, dynamic sorption and desorption processes were occurring between constituents in the soil seepage water and the soil matrix. This study demonstrates soil seepage water has posed a high risk to the groundwater, and effective protection is urgently needed.

\section{Keywords: Polycyclic aromatic hydrocarbons; Karst hydrology; Soil seepage water;}

\section{Dissolved organic carbon; Ecological risk assessment}

In this study, we found the concentrations of PAHs in soil seepage water increased with depth, and PAHs in soil seepage water has posed a high risk to the groundwater.

\section{Introduction}


Polycyclic aromatic hydrocarbons (PAHs) are typical of persistent organic pollutants; they are highly toxic and are suspected of being carcinogenic and mutagenic (Chen et al., 2011; Niu et al., 2017). Previous studies have demonstrated that 2-3 ring PAHs are acutely toxic, but less mutagenic than 4-6 ring PAHs, the latter of which are both mutagenic and carcinogenic (Bolden et al., 2017). Therefore, the U.S. Environmental Protection Agency (USEPA) has listed 16 PAHs as priority control pollutants (Ball and Truskewycz, 2013). PAHs are primarily formed by incomplete combustion or pyrolysis of organic matter, and anthropogenic activities (e.g., the incomplete combustion of fossil fuels, coke production, various industries) are their main sources (Liu et al., 2016).

PAHs emitted into the atmosphere can be transported over long distances prior to their deposition over terrestrial and aquatic surfaces. Soils are the main repository of PAHs in terrestrial systems (Marzooghi and Toro, 2017). Due to their low degradability and hydrophobicity, PAHs may be accumulated and stored in soils for decades. However, PAHs can be remobilized by runoff, or transported to groundwater by downward migrating soil seepage waters. Thus, PAHs have the potential to seriously degrade water and soil quality, and both human and biotic health can be damaged by drinking contaminated water, ingesting contaminated soils and/or inhaling PAHs emitted from soils (Paris et al., 2018; Drwal et al., 2019). The potential impact of PAHs is controlled in part by PAH sorption, and transformation processes, which influence the concentrations and migration of PAHs in soil, and emission of PAHs from the soil. Schwarz et al. (2011) suggested that PAHs were effectively retained in soils even 
in highly vulnerable karst catchments, and only during early spring (e.g. snowmelt events) can particle- facilitated transport lead to PAH concentration in groundwater above the drinking water limits. However, the infiltration of PAHs from overlying soil to groundwater has the potential to greatly effect groundwater quality. Due to the rapid downward movement of soil seepage water in some karst terrains (Yuan, 2000; Yang et al., 2012), PAHs sorbed to the soil matrix may be desorbed and migrate to groundwater. Organic matter in the soil matrix has the potential to dissolve in soil seepage water, forming DOM. Hence, soil-bound PAHs may be remobilized by its complexation with DOM as DOM is released from the soil matrix. Thus, the quality of mobile soil water and its DOM content have an important effect on groundwater.

Groundwater in karst terrains is an important resource as approximately $25 \%$ of the world's population uses it as a domestic water supply (Ford and Williams, 2007). There are approximately 2836 underground rivers mapped in karst terrains in south China, with a total length of about $13919 \mathrm{~km}$. Their multi-annual mean discharge is about $1482 \mathrm{~m}^{3} / \mathrm{s}$, and they provide about $1808 \times 10^{8} \mathrm{~m}^{3} / \mathrm{a}$ of water (Yang, 1985). Our study area is located within the karstic catchment of the Laolongdong (LLD) karst underground river in Chongqing, southwest China. The catchment is typical of many karst terrains, being characterized by a thin layer of surface soil that overlies soluble rocks possessing enormous interconnected fissures. These properties allow for the rapid infiltration of precipitation and rapid movement of soil water (Yuan, 2000). Therefore, the karst groundwater system is particularly vulnerable to contamination. Chongqing is the largest municipal economic center in southwest China and an important 
communications hub. It has a population of 30 million, and is located along the upper reaches of the Yangtze River. Chongqing also has many heavy industrial facilities and a high traffic density. Previous studies have found higher airborne PAH concentrations in Chongqing compared with other cities in China (Zhao et al., 2014), and the concentrations of 1-OHPyr in urinary samples from children who live in Chongqing are higher than they are in other countries (Liu et al., 2017). Intensive urbanization in Chongqing led to the discharge of large amount of PAHs into soils and then into groundwater (Lan et al., 2016). Recently, Lan et al. (2018) reported that the concentrations of PAHs in the topsoil, groundwater and sediments were elevated in the LLD underground river system. These elevated PAHs concentrations will pose an increasing burden on groundwater quality and the health of the underground river ecosystem (Lan et al., 2018). Our previous study has shown the ecological risk of PAHs in groundwater in karst system were much higher than those in non-karst areas (Lan et al., 2020).

However, data pertaining to the concentration, seasonal variation, vertical migration and the ecological risk of PAHs in soil seepage water within karst terrains in general, and the LLD catchment in particular, are scarce. The primary aims of this study were to (1) investigate the vertical migration and variation of PAHs in soil seepage water within the LLD karst underground river system; (2) identify the factors controlling the vertical migration of PAHs within soil seepage water; and (3) assess the ecosystem risk posed by PAHs in both soil and soil seepage water using risk quotients. 


\section{Material and methods}

\subsection{Sample sites and collection}

Soil and soil seepage water samples were collected from 6 sites (S1-S3 for soil; W1-W3 for soil seepage water), which were located directly above the LLD underground river (Fig.1). The study area was reported in detail in our previous paper (Lan et al., 2018). Each soil sampling site is located directly adjacent to soil seepage water sampling sites. Sites S1 and W1 were located in the upper reaches, S2 and W2 in the middle reaches, and S3 and W3 in the lower reaches of the LLD underground river. Land use at S1 and S2 consisted of vegetable fields, whereas land use at S3 consisted of shrub vegetation. S1, S2 and S3 soil profiles were over $100 \mathrm{~cm}$. The mean values of TOC at S1, S2 and S3 were $23.4 \pm 8.3 \mathrm{~g} / \mathrm{kg}, 31.2 \pm 8.1 \mathrm{~g} / \mathrm{kg}$ and $24.6 \pm 14.4 \mathrm{~g} / \mathrm{kg}$, respectively; $\mathrm{pH}$ at $\mathrm{S} 1, \mathrm{~S} 2$ and $\mathrm{S} 3$ was $6.86 \pm 0.87,7.75 \pm 0.14,7.37 \pm 0.44$, respectively (Xie, 2017). The soil seepage water collection equipment (made by the Institute of Karst Geology, Chinese Academy of Geological Sciences) was placed at three depths at each site, 20, 50 and $80 \mathrm{~cm}$ below the ground surface, and three seepage water collection devices were placed at each depth. The seepage water samples from the same depth were mixed prior to analysis; thus, the concentration reported for PAHs represents an average value from the three seepage water collection devices for each sampling site. The installation of soil seepage water collection device did not damage the soil layer. Soil samples were collected in May 2015. Soil seepage water samples were collected using soil seepage water collection device monthly from May 2015 to April 2016. In total, 33 soil samples 101 soil seepage water samples were collected in this study area. 
The sample collection method of soil was reported in detail in our previous paper (Sun et al., 2019). The sample collection method of soil seepage water was described elsewhere (Chen and Li, 2018).

\subsection{Sample preparation and PAH analysis}

Sample extraction, instrument analysis and analytical quality controls were reported in detail in our previous paper (Sun et al., 2019). They will only be described briefly here. After freeze drying, soil samples were extracted by accelerated solvent extraction (ASE350, Thermo Scientific), cleaned via aluminum oxides and silica gel column chromatography, and analyzed by GC-MS (Agilent 7890A GC, 5975C MSD) in selected ion monitoring (SIM) modes. Soil seepage water samples were extracted by automatic solid-phase extraction system (SPE-DEX 4790, Horizon technology), then analyzed by GC-MS with internal PAH standards. The 16 priority PAHs monitored in this study were: naphthalene (Nap), acenaphthylene (Acy), acenaphthene (Ace), fluorene (Flu), phenanthrene (Phe), anthracene (Ant), fluoranthene (Fla), pyrene (Pyr), chrysene (Chry), benzo(a)anthracene (BaA), benzo(k)fluoranthene (BkF), benzo(b)fluoranthene $(\mathrm{BbF})$, benzo(a)pyrene $(\mathrm{BaP})$, dibenzo(a,h)anthracene $(\mathrm{DaA})$, and indeno(1,2,3-cd)pyrene (InP). The 16 PAHs mixed stock standard was purchased from Dr. Ehrenstorfer GmbH Inc., Germany.

\subsection{Quality control and quality assurance}

Method detection limits for $10 \mathrm{~g}$ solid samples ranged from 0.5 to $3.1 \mathrm{ng} / \mathrm{g}$ dry weights and varied from 0.2 to $1.5 \mathrm{ng} / \mathrm{L}$ for the $1 \mathrm{~L}$ water samples with GC-MS SIM mode. Average recovery rates for surrogate standards were $70 \pm 5 \%, 80 \pm 5.6 \%, 92 \pm$ 
$7.5 \%, 95 \pm 12 \%, 96 \pm 8.5 \%$ for naphthalene-d8, acenaphthene-d10, phenanthrene-d10, for chrysene-d12, and perylene-d12, respectively. PAHs concentration of each sample were recovery-corrected.

\subsection{DOC analysis}

DOC in soil seepage water was measured by a total organic carbon (TOC) analyzer (JENA 3100 TOC meter). DOC was determined in triplicates with a relative standard deviation less than $1 \%$.

\subsection{Ecological risk assessment}

PAHs in soil seepage water can be adsorbed by plant roots and soil organisms more easily than from the soil matrix (Wells et al., 2005; Gao et al., 2008; Levy et al., 2017). Thus, it is necessary to assess the ecological risk of PAHs in soil seepage water. A risk quotient (RQ) was used here to assess potential risks posed by PAHs in soil seepage water. The RQ is defined as the ratio of certain pollutants to the corresponding concentration of the pollutant in the medium, and is extensively used for the evaluation of the undesirable impacts caused by environmental pollutants in an ecological system (Kalf et al., 1997; Cao et al., 2010). RQ can be used to assess the ecological risk of PAHs in water, sediments or soils, and to compare the values among different medium (Kalf et al., 1997). The RQ was calculated as follows:

$$
\mathrm{RQ}=\frac{\mathrm{C}_{\mathrm{PAHs}}}{\mathrm{C}_{\mathrm{QV}}}
$$

where $\mathrm{CPAHs}_{\mathrm{PA}}$ was the concentration of certain PAHs in a given medium and $\mathrm{C}_{\mathrm{QV}}$ was the corresponding quality values for a given PAHs in the medium.

Furthermore, RQ of the negligible concentration $\left(\mathrm{RQ}_{(\mathrm{NCs})}\right)$ and maximum 
permissible concentration $\left(\mathrm{RQ}_{(\mathrm{MPC})}\right)$ for individual PAHs in soil seepage water were also determined using the equations below:

$$
\begin{gathered}
\mathrm{RQ}_{\mathrm{NCs}}=\frac{\mathrm{C}_{\mathrm{PAHs}}}{\mathrm{C}_{\mathrm{QV}(\mathrm{NCs})}} \\
\mathrm{RQ}_{\mathrm{MPCs}}=\frac{\mathrm{C}_{\mathrm{PAHs}}}{\mathrm{C}_{\mathrm{QV}(\mathrm{MPCs})}}
\end{gathered}
$$

where $\mathrm{C}_{\mathrm{QV}(\mathrm{NCs})}$ was the quality values of the negligible concentrations of PAHs, and $\mathrm{CQV}(\mathrm{MPCs})$ was the maximum permissible concentrations of PAHs.

The ecosystem risk of $\sum$ PAHs was calculated using the method put forth by Cao et al (2010). This method eliminates the problem that ecological risk of individual PAHs was neglected when calculating ecological risk using the approach by Kalf et al (1997).

The modified $\mathrm{RQ}_{\Sigma \mathrm{PAHs}}, \mathrm{RQ}_{\Sigma \mathrm{PAHs}(\mathrm{NCs})}$ and $\mathrm{RQ}_{\Sigma \mathrm{PAHs}(\mathrm{MPCs})}$ were calculated as follows:

$$
\begin{gathered}
\mathrm{RQ}_{\sum \mathrm{PAHs}}=\sum_{\mathrm{i}=1}^{16} \mathrm{RQ}_{\mathrm{i}}\left(\mathrm{RQ}_{\mathrm{i}} \geq 1\right) \\
\mathrm{RQ}_{\sum \text { PAHs }(\mathrm{NCs})}=\sum_{\mathrm{i}=1}^{16} \mathrm{RQ}_{\mathrm{i}(\mathrm{NCs})}\left(\mathrm{RQ}_{\mathrm{i}(\mathrm{NCs})} \geq 1\right) \\
\mathrm{RQ}_{\sum_{\mathrm{PAHs}(\mathrm{MPCs})}}=\sum_{\mathrm{i}=1}^{16} \mathrm{RQ}_{\mathrm{i}(\mathrm{MPCs})}\left(\mathrm{RQ}_{\mathrm{i}(\mathrm{MPCs})} \geq 1\right)
\end{gathered}
$$

Based on the ecological risk assessment of 16 individual PAHs, $\mathrm{RQ}_{\Sigma \mathrm{PAHs}(\mathrm{NCs})}$ and $\mathrm{RQ}_{\Sigma \mathrm{PAHs}(\mathrm{MPCs})}$ values were calculated by summing $\mathrm{RQ}_{(\mathrm{NCs})}$ and $\mathrm{RQ}_{(\mathrm{MPCS})}$ of individual PAH which exhibited RQ that were greater than 1. The ecological risk of PAHs in soil seepage water within the LLD karst underground river system was evaluated and compared with the reference quality values reported by Kalf et al., (1997) and Cao et al., (2010). 


\section{Results and discussion}

\subsection{Vertical variations and composition of PAHs in soil profiles}

The PAHs at the three sites predominantly accumulated on soil materials at depths of $0-40 \mathrm{~cm}$ below the ground surface (Fig. 2). Concentrations then decreased with increasing depth, suggesting that PAHs could be effectively retained in the soil even in a highly vulnerable karst catchment. The concentration of PAHs varied widely within the three soil profiles. Variations ranged at $\mathrm{S} 1$ from 44.9 to $406 \mathrm{ng} / \mathrm{g}$, with a mean concentration of $154 \mathrm{ng} / \mathrm{g}$, from 206 to $2127 \mathrm{ng} / \mathrm{g}$ at S2, with a mean concentration of $698 \mathrm{ng} / \mathrm{g}$, and from 43.2 to $1902 \mathrm{ng} / \mathrm{g}$ with a mean concentration of $559 \mathrm{ng} / \mathrm{g}$ at S3. At a depth of 20 to $40 \mathrm{~cm}$, which corresponded to the boundary between the humic or plough layer and the mineral soil, a sharp decrease in PAH concentrations occurred. The PAH concentrations were less than $76 \mathrm{ng} / \mathrm{g}$, with a mean concentration $69.1 \mathrm{ng} / \mathrm{g}$ in soil layers beneath $20 \mathrm{~cm}$ at S1; at S3 the mean concentration was $58.5 \mathrm{ng} / \mathrm{g}$ in soil layers beneath $40 \mathrm{~cm}$. However, at S2, a sharp decrease in PAH concentrations occurred at the depth of $2 \mathrm{~cm}$, changing from $2127 \mathrm{ng} / \mathrm{g}$ (at $2 \mathrm{~cm}$ ) to $917 \mathrm{ng} / \mathrm{g}$ (at $10 \mathrm{~cm}$ ). The mean PAHs concentration was $555 \mathrm{ng} / \mathrm{g}$ in the soil layers beneath $2 \mathrm{~cm}$ at $\mathrm{S} 2$, and was much higher than at S1 and S3. Furthermore, the PAH concentration was $388 \mathrm{ng} / \mathrm{g}$ in soil at $100 \mathrm{~cm}$ in depth at S2, and was close to the concentration of PAHs (404 ng/g) in 0-2 cm soil layer at $\mathrm{S} 1$. However, the concentration of PAHs in soil at $100 \mathrm{~cm}$ in depth at S1 and S3 were only $67.4 \mathrm{ng} / \mathrm{g}$ and $43.6 \mathrm{ng} / \mathrm{g}$, respectively. These data showed that the mobility of PAHs at S2 was much higher than at the other two soil profiles.

Although data from the soil profiles showed that the PAHs were effectively 
retained in the soils, the PAH concentrations in soil seepage water increased in the following order: $20 \mathrm{~cm}<50 \mathrm{~cm}<80 \mathrm{~cm}$ (except at $\mathrm{W} 2$ during the rainy season). These data show that soil seepage water might play a key role in the vertical migration of PAHs in soils in karst terrains. Due to the thin soil layer and high permeability (Yuan, 2000; Yang et al., 2012), some of the PAHs in soil might had been dissolved in soil seepage water during its downward movement, and was transported to groundwater. From this point, the overlying soil in karst terrains had lost the potential to protect groundwater to some degree.

The 4-, 5- and 6-ring PAHs dominated the PAHs composition (Fig. S1). The percentage of 4-, 5- and 6-ring PAHs at S2 was the highest among the 3 soil profiles, with a mean of $88 \%$. For the 2- and 3-ring PAHs, the percentage at S1 was the highest among the 3 soil profiles, with a mean of $34.6 \%$. At S1, PAH composition fluctuated greatly from $0 \mathrm{~cm}$ to $70 \mathrm{~cm}$; however, within the $80-90 \mathrm{~cm}$ soil layers, PAH composition was uniform. At S2, the 4-ring PAHs accounted from $9.6 \%$ to $23.6 \%$ of the total, whereas 5- and 6-ring PAHs constituted $62 \%$ to $82.9 \%$ of the PAHs. The 2- and 3-ring PAHs contributed a relative minor percentage of the PAHs (7.4-18.7\%). More uniform

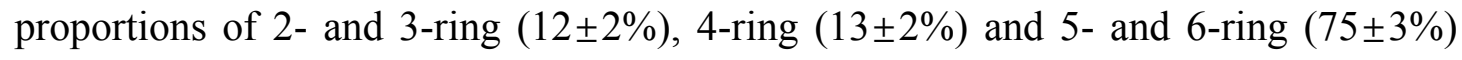
PAHs were observed in all soil layers at S2. At S3, a decrease in 5- and 6-ring PAHs, and an increase in 2-, 3- and 4-ring PAHs were observed from $0 \mathrm{~cm}$ to $100 \mathrm{~cm}$ in depth.

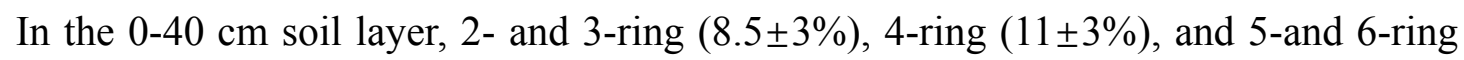
$(81 \pm 6 \%)$ PAHs exhibited uniform values. However, in the $40-100 \mathrm{~cm}$ soil layer, the PAH composition varied greatly. 
The vertical variations of PAHs in soil seepage water are shown in Fig. 3. Fifteen PAHs (all except DaA) were detected in soil seepage water. PAH concentrations in soil seepage water at W1 ranged from106 to $4649 \mathrm{ng} / \mathrm{L}$; the mean concentration was 1324 ng/L. At W2, the concentrations ranged from 239 to $3940 \mathrm{ng} / \mathrm{L}$, whereas the mean concentration was $1029 \mathrm{ng} / \mathrm{L}$. The range of PAH concentrations at W3 was 151 to 2958 $\mathrm{ng} / \mathrm{L}$; the mean concentration was $870 \mathrm{ng} / \mathrm{L}$. With the exception of site W2, the PAH concentrations in soil seepage water increased with depth in the following order: $20 \mathrm{~cm}$ $<50 \mathrm{~cm}<80 \mathrm{~cm}$ (Fig. 3). This trend indicates that PAHs were continuously dissolved in the soil seepage water from soil matrix as the water moved vertical downward in depth, the concentrations of PAHs in soil seepage water remained nearly constant support the argument that PAH concentrations in soil seepage water at $\mathrm{W} 2$ at $80 \mathrm{~cm}$ in depth were diluted during the rainy season by groundwater within the zone of saturation. 
263

The mean concentrations of PAHs in soil seepage water at W1 and W3 at depths of 20, 50 , and $80 \mathrm{~cm}$ all systematically increased downward during the rainy season and the dry season (Fig. 3).

The composition of PAHs for a given year was investigated by ring number in soil seepage water from the LLD underground river system (Fig. S2). Three-ring PAHs dominated at different depths at W1, W2 and W3. On average, 3-ring PAHs occupied $76.2 \%, 78 \%$ and $58.2 \%$ of total PAHs in soil seepage water at $\mathrm{W} 1$, W2 and $\mathrm{W} 3$, respectively. Two-ring, 4-ring and 5-ring PAHs occupied on average 11.3\%, 8.4\% and $4.1 \%$ in soil seepage water at $\mathrm{W} 1$, and $16.3 \%, 14.9 \%$ and $9.9 \%$ at $\mathrm{W} 3$, respectively. However, at W2 the percentage of PAHs in soil seepage water followed a different sequence. Two-ring, 5-ring and 4-ring PAHs occupied on average 8.8\%,8.2\% and 5.1\%, respectively. The relative contents of 6-ring PAHs were the lowest. In fact, 6-ring PAHs could not be detected in all soil seepage water samples. An exception was soil seepage water collected in August, 2015 from $50 \mathrm{~cm}$ in depth at W3. At W1 and W2, Flu dominated the PAHs composition (41.9\% and 51.2\%, respectively), followed by Phe (22\%), Nap (11.3\%) and Ace (7.7\%) at W1, and Phe (13\%), Ace (10.4\%) and Nap $(8.8 \%)$ at $\mathrm{W} 2$. However, at $\mathrm{W} 3,23.9 \%$ of the total PAHs concentration was represented by Phe, followed by Flu (19.1\%), Nap (16.3\%) and Ace (7.8\%). Different transport mechanisms may be responsible for the variation in composition of the PAHs in soil seepage water at different depths between the three sample sites. At W1, 5-ring PAHs were only detected in soil seepage water at 20 and $50 \mathrm{~cm}$ depths during the dry season, accounting for a mean percentage of $12 \%$ and $16 \%$, respectively. At W2, the percentage 
of 5-ring PAHs in soil seepage water increased from $20 \mathrm{~cm}$ depth to $50 \mathrm{~cm}$ depth; however, from $50 \mathrm{~cm}$ to $80 \mathrm{~cm}$ depth, the percentage of 5-ring PAHs decreased. At W3, the percentage of 5-ring PAHs in soil seepage water exhibited a decrease from $20 \mathrm{~cm}$ to $80 \mathrm{~cm}$ in depth. These trends suggest 5 -ring PAHs were re-adsorbed by soil matrix during the migration of soil seepage water from $20 \mathrm{~cm}$ to $80 \mathrm{~cm}$ in depth. At W2, even at $80 \mathrm{~cm}$ depth, the percentage and detection ratio of 5-ring PAHs in soil seepage water were all higher than at $\mathrm{W} 1$ and $\mathrm{W} 3$. These higher values may indicate that 5-ring PAHs were easier to leach into soil seepage water at $\mathrm{W} 2$ than at $\mathrm{W} 1$ and $\mathrm{W} 3$. This may be due to the fact that the soil profile at $80 \mathrm{~cm}$ in depth at $\mathrm{W} 2$ was located in the zone of saturation during the rainy season, allowing groundwater to more easily leach 5-ring PAHs from the soil matrix. During the dry season, the percentage of 5-ring PAHs was higher than during the rainy season (Fig. S2). The results indicate 5-ring PAHs were easier to desorb into soil seepage water during the dry season than the rainy season. Schwarzenbach and Westall (1981) found that the sorption and desorption of nonpolar organic compounds from soil were slow kinetic processes. Due to the higher hydraulic conductivity of soil during the rainy season, the rain water would quickly penetrate the soil layer. The rapid movement of the water would not allow enough time for PAHs to desorb from the soil matrix. This conclusion is supported by the percentage of 5-ring PAHs in soil seepage water during a rain storm in July, 2015 (Fig. S2). During the storm event, precipitation quickly moved into the underground river, and 5-ring PAHs could not be detected in most soil seepage water samples (exceptions occurred $50 \mathrm{~cm}$ depth at $\mathrm{W} 2$ and $20 \mathrm{~cm}$ depth at $\mathrm{W} 3$ ). 
S1, S2) showed that they differed significantly; the PAHs in soil seepage water were dominated by LMW PAHs (2- and 3-ring PAHs), whereas that of soil was dominated by HMW PAHs (5- and 6-ring PAHs). Since LMW PAHs possess lower octanol-water partitioning coefficients than HMW PAHs, they tend to be more enriched in the soil seepage water. In addition, HMW PAHs are more resistant to degradation processes in the soil (Simarro et al., 2013). Due to the re-adsorption of HMW PAHs in soil seepage water by the soil matrix, the deep soil layers also exhibited higher percentages of HMW PAHs.

\subsection{Factors controlling PAHs in soil seepage water}


difference between the concentration and solubility decreased. Within the range of 3.374.54 of $\log \mathrm{K}_{\mathrm{ow}}$, the solubilities of PAHs were 3.3-6.2 $\log$ units higher than the concentrations. Within the range of 5.22-5.86 of $\log \mathrm{K}_{\mathrm{ow}}$, the solubilities of PAHs were 2.9-4.6 log units higher than the concentration. However, within the range of 6-6.75 of $\log \mathrm{K}_{\mathrm{ow}}$, the solubilities of PAHs were $0.8-2.8 \log$ units higher than the concentrations. These results showed that all PAHs did not reach the equilibrium of dissolution, but HMW PAHs (5.8-6.75 of $\log \mathrm{K}_{\mathrm{ow}}$ ) were closer to equilibrium dissolution than LMW and MMW PAHs. Therefore, the capacity of dissolving LMW and MMW PAHs in soil seepage water were greater than HMW PAHs. LMW and MMW PAHs can be easier dissolved in the soil seepage water from soil matrix as the water moves vertical downward through the profiles (Perrette et al., 2013; Levy et al., 2017).

\subsubsection{Effect of DOM on PAHs in soil seepage water}

Previous studies have shown that the environmental fate and behavior of hydrophobic organic compounds in soil is ultimately determined by the physicochemical properties of each compound and the properties of the soil, such as its organic matter content (Chiou et al, 1983; Sverdrup et al., 2002; Chen et al., 2017). With regards to the composition of the soil, the sorption of hydrophobic organic compounds from water is primarily governed by its sorption onto soil organic matter; sorption by the soil mineral fraction is relatively unimportant (Chiou et al., 1983). Soil organic matter tends to dissolve in infiltrating rainwater, forming dissolved organic matter (DOM). Generally, DOM is quantified through measurement of dissolved organic carbon (DOC). Due to the prevalence and relative stability of DOM in water, it 
is possible that it can significantly affect PAH sorption. Many studies have indicated that DOM enhances the apparent water solubility and mobility of highly hydrophobic contaminants, such as PAHs (Rav-Acha and Rebhun, 1992; McGinley et al., 1996; in solubility results from the binding of DOM with organic pollutants to form humicsolute complexes. Thus, soil-bound PAHs may become remobilized in association with $\mathrm{DOM}$ as the latter is released into the water.

In order to determine the role of DOM in the transport of PAHs in soil seepage water, a Pearson correlation analysis was applied to assess the relationship among total PAHs, (2+3) ring PAHs, 4- and 5-ring PAHs with DOC in soil seepage water (Figs. 5, S3). At W1 and W3, no significant correlations were observed between total PAHs, (2+3) ring, 4-ring PAHs and DOC. However, significant correlations were found between total PAHs, (2+3) ring, 4-ring PAHs and DOC at W2. Due to the predominance of $(2+3)$ ring PAHs in soil seepage water, the correlation between them and DOC was similar to that between total PAHs and DOC. At W1, W2 and W3, significant correlations were observed between 5-ring PAHs and DOC. This is consistent with the findings of Moeckel et al. (2014) in an upland stream in the U.K. The lack of correlation between DOM and both LMW and MMW PAHs (4-ring PAHs) at W1 and W3 indicates that their input into soil seepage water was not linked to DOM. Rather, the input of PAHs to the soil seepage water from the soil matrix occurred through dissolution. Johnson and Amy (1995) found that soil-derived humic materials had much more effect on the transport and desorption of PAHs than aquatic-derived humic materials, and the 
effects were greater for the more hydrophobic PAHs than for PAHs of lower hydrophobicity. Thus, the higher hydrophobicity and stronger affinity of 5-ring PAHs for DOM led to the input of 5-ring PAHs to be linked to DOM inputs, which indicates these PAHs were released simultaneously from the soil matrix to soil seepage water. The correlation between PAHs and DOC was highest at W2 among the three sites, suggesting that PAHs at S2 were the most mobile among the three soil profiles. This enhanced mobility can explain the more uniform proportions of PAHs observed between the soil layers at S2. The data show that DOM can enhance the mobility of HMW PAHs in soil in this study area. However, due to hydrophobicity, PAHs can be sorbed onto soil organic matter (SOM), which could increase the sorption and reduce the mobility of HMW PAHs associated with the DOM (Johnson and Amy, 1995). Furthermore, McCarthy and Jimenez (1985) showed that the binding of BaP to dissolved humic material was completely reversible and the extent of reversibility was unrelated to the sorption time. Thus, HMW PAHs dissociated from DOM could be sorbed onto SOM, which reduced the mobility of HMW PAHs, and led to lower detection ratios of HMW PAHs in soil seepage water at greater depths.

Based on the above results, we can speculate that PAHs can be continuously dissolved in the soil seepage water from soil matrix as the water moved vertical downward through the profiles. During this process, dynamic sorption and desorption processes were occurring between constituents in the soil seepage water and the soil matrix. The processes may not have reached chemical equilibrium, and competitive solute sorption would occur. In this case, DOM played an important role, and DOM in 
soil seepage water was an important carrier of PAHs, especially for HMW PAHs.

\subsection{Ecological risk assessment of PAHs in soil seepage water}

For evaluation of the ecological risk by PAHs in soil seepage water in karst terrains, $\mathrm{RQ}_{(\mathrm{NCs})}$ and $\mathrm{RQ}(\mathrm{MPCs})$ for individual PAHs and PAHs were calculated and compared with their reference quality values in this study. In principle, if $\mathrm{RQ}_{(\mathrm{NCs})}$ is $<1$ for individual PAH, then the risk might be probably negligible concern. When $\mathrm{RQ}_{(\mathrm{MPCs})}$ is $>$ 1 , then the risk is high and immediate actions should be taken. When $\mathrm{RQ}(\mathrm{NCs})$ is $>1$ and $\mathrm{RQ}_{(\mathrm{MPCs})}$ is $<1$, then the risk associated with PAHs contamination is mid-line and some control measures or remedial actions need be undertaken. The ecological risk classification of PAHs is shown in Table S1. The methodology for risk evaluation is detailed elsewhere (Kalf et al., 1997; Cao et al., 2010).

The mean values of $\mathrm{RQ}_{(\mathrm{NCs})}$ and $\mathrm{RQ}_{(\mathrm{MPCs})}$ of PAHs at different soil seepage water depths are listed in Tables S2 and S3; At W1, RQ(MPCs) of individual PAHs were all less than 1.0 in soil seepage water, except for Flu at depths of $20 \mathrm{~cm}$ and $50 \mathrm{~cm}$ (RQ(MPCs) $=5.2$ and 6.5, respectively) (Compare Tables S2, S3 with S1). These RQ values indicate that Flu may pose a severe threat to plants and soil organisms. However, the mean values of RQ(MPCs) of Acy, Ace, Flu, Phe, Fla, and Pyr in soil seepage water at $80 \mathrm{~cm}$ in depth were equal to or higher than 1.0, indicating that the ecosystem was at high risk and suffered from severe toxicity. Remedial actions should be undertaken as soon as possible. At W2, the mean values of $\mathrm{RQ}_{(\mathrm{MPC})}$ of Flu and BbF in soil seepage water at $20 \mathrm{~cm}$ in depth, Flu, BbF, and BkF at $50 \mathrm{~cm}$ in depth, and Acy, Ace, Flu, and BbF at 80 $\mathrm{cm}$ in depth were higher than 1.0, again indicating the ecosystem was at severe risk. At 
W3, the mean values of $\mathrm{RQ}_{(\mathrm{MPCs})}$ for Flu and $\mathrm{BkF}$ in soil seepage water at $20 \mathrm{~cm}$ in depth, Flu and BbF at $50 \mathrm{~cm}$ in depth, and Acy, Ace, Flu, Phe, Pyr, BaA, and BbF at 80 $\mathrm{cm}$ in depth were higher than 1.0, indicating severe risk in $\mathrm{W} 3$ soil seepage water. The mean values of $\mathrm{RQ}_{(\mathrm{NCs})}$ of Nap, Ace, Flu, Phe, and Pyr at W1-3 in soil seepage water were higher than 1.0, indicating that these PAHs posed a moderate level of ecological risk. In contrast, Chry, $\mathrm{BaP}, \mathrm{BaA}$, and $\mathrm{BgP}$ only posed an ecological risk at particular sites. DaA showed no ecological risk at any site (Compare Tables S2, S3 with S1).

Figure 6 shows that 3-ring, 4-ring, and 5-ring PAHs contributed to the main ecological risk burdens in soil seepage water. However, different ring PAHs had different ecological risk burdens in different sampling sites. At W1, 3-ring PAHs contributed the most ecological risk burdens. These values were similar to their contributions to PAH concentration (compare Fig. 6 with S1). At W2, 3-ring and 5-ring PAHs contributed the main risk to the ecosystem (Fig. 6). At a depth of $20 \mathrm{~cm}$ and 80 $\mathrm{cm}$, the contribution of 3-ring PAHs in soil seepage water to ecological risk was higher than that of 5-ring PAHs; however, at $50 \mathrm{~cm}$ depth, the contribution of 5-ring PAHs in soil seepage water was higher than that of 3-ring PAHs. At W3, 3-ring and 5-ring PAHs posed the most ecological risk in soil seepage water; however, at $80 \mathrm{~cm}$ in depth, 4-ring PAHs posed a moderate contribution to risk (16.6\%) (Fig. 6). Therefore, HMW PAHs accounted for non-negligible proportions of $\mathrm{RQ}_{(\mathrm{NCs})}$ at some sampling sites, although these PAHs accounted for very low proportions of PAH concentration (Fig. S1). In general, 3-ring PAHs accounted for the most ecological risk with a mean value of 68.3\%. The 2-ring, 4-ring and 5-ring PAHs exhibited mean values of $0.58 \%, 7.3 \%$ and $23.3 \%$, 
respectively.

$\mathrm{RQ}_{(\mathrm{MPCs})}$ calculated using the $\sum \mathrm{PAHs}$ in soil seepage water were all higher than 1.0. $\mathrm{RQ}_{(\mathrm{NCs})}$ of $\sum \mathrm{PAHs}$ were all higher than 800 in soil seepage water, except for $\sum \mathrm{PAHs}$ at W1 and $\mathrm{W} 3$ at a depth of $20 \mathrm{~cm}$, indicating severe risk for plants and soil organisms. $\mathrm{RQ}_{(\mathrm{NCs})}$ of $\sum \mathrm{PAHs}$ at $\mathrm{W} 1$ and $\mathrm{W} 3$ at a depth of $20 \mathrm{~cm}$ depth were less than 800 , but higher than 1.0, indicating medium risk. At W1 and W3 (Table S2; Fig. 6), the mean values of ecological risk were the lowest in soil seepage water at a depth of $20 \mathrm{~cm}$, followed by those at $50 \mathrm{~cm}$ depth. The highest values were at $80 \mathrm{~cm}$ depth. However, at $\mathrm{W} 2$, the risk value in soil seepage water exhibited the following order: $20 \mathrm{~cm}<50$ $\mathrm{cm} \approx 80 \mathrm{~cm}$ in depth. The risk order was consistent with the order of mean $\sum$ PAHs concentration, although its risk compositions were different from the compositions of ¿PAHs concentrations. Apparently, the ecological risks in soil seepage water at $20 \mathrm{~cm}$ depth were lower than those at $50 \mathrm{~cm}$ or $80 \mathrm{~cm}$ depth. Furthermore, at $20 \mathrm{~cm}$ and $50 \mathrm{~cm}$ depth, the average risk of $\sum$ PAHs at $\mathrm{W} 2$ were consistently the highest. At $80 \mathrm{~cm}$ depth, the average risk of $\sum$ PAHs in soil seepage water at W1 and W3 were similar and much higher than at W2. The above results show that the ecological risks of soil seepage water increased with depth, which means soil seepage water will pose a high risk to the groundwater. $\mathrm{RQ}_{(\mathrm{NCS})}$ of $\sum \mathrm{PAHs}$ in the soil matrix were all much less than $\mathrm{RQ}_{(\mathrm{NCs})}$ of $\sum$ PAHs in soil seepage water (Fig. 6). These results indicate that the ecological risk in soil was much less than that in soil seepage water.

\section{Conclusions}


This study shows that soil seepage water played a key role in the vertical migration

462

463

of PAHs in soils within a karst terrain. Due to the region's thin soils and high permeability, much of the PAHs in soil were dissolved in soil seepage water as the latter migrated vertically downward toward and into groundwater. Thus, overlying soil in this karst terrain had lost its ability to protect groundwater from PAH contamination. The concentration of PAHs in soil seepage water increased downward such that: $20 \mathrm{~cm}<$ $50 \mathrm{~cm}<80 \mathrm{~cm}$ (except at $\mathrm{W} 2$ during the rainy season). PAH composition in soil seepage water was dominated by LMW PAHs, whereas that in the soil matrix was dominated by HMW PAHs. HMW PAHs and DOM were released simultaneously from the soil matrix to the soil seepage water, suggesting that DOM in the soil seepage water is an important carrier of PAHs, especially for HMW PAHs. Ecological risk assessment indicated that the ecological risk in soil was much less than that in soil seepage water and the ecological risks in soil seepage water increased as soil seepage water migrated vertically downward. These trends indicate that soil seepage water will pose a high risk to the groundwater.

\section{Acknowledgement}

This study was supported by the National Key Research and Development Program of China (No. 2016YFC0502306 and 2016YFD0800305), the Fundamental Research Funds for the Central Universities (No. XDJK2019B067), the National Natural Science Foundation of China (No. 41601584 and 41761091), and the Basic Research and Frontier Exploration of Chongqing Science \&Technology Commission (cstc2016jcyjA0921). 


\section{Reference}

485

486

487

488

489

490

491

492

493

494

495

496

497

498

499

500

501

502

503

504

505

506

507

508

509

510

511

512

Ball, A., Truskewycz, A., 2013. Polyaromatic hydrocarbon exposure: an ecological impact ambiguity. Environ. Sci. Pollut. Res. Int. 20, 4311-4326.

Bolden, A.L., Rochester, J.R., Schultz, K., Kwiatkowske, C.F., 2017. Polycyclic aromatic hydrocarbons and female reproductive health: a scoping review. Reprod. Toxicol. 73, 61-74.

Cao, Z., Liu, J., Luan, Y., Li, Y., Ma, M., Xu, J., Han, S., 2010. Distribution and ecosystem risk assessment of polycyclic aromatic hydrocarbons in the Luan River, China. Ecotoxicology, 19, 827-837.

Chen, C.J., Li, T.Y., 2018. Geochemical characteristics of cave drip water respond to ENSO based on a 6-year monitoring work in Yankou Cave, Southwest China. Journal of Hydrology, 561, 896-907.

Chen, W., Wang, H., Gao, Q., Chen, Y., Li, S., Yang, Y., Werner, D., Tao, S., Wang, X., 2017. Association of 16 priority polycyclic aromatic hydrocarbons with humic acid and humin fractions in a peat soil and implications for their long-term retention. Environ. Pollut. 230, 882-890.

Chen, Y.J., Feng, Y.L., Xiong, S.C., Liu, D.Y., Wang, G., Sheng, G.Y., Fu, J.M., 2011. Polycyclic aromatic hydrocarbons in the atmosphere of Shanghai, China. Environ. Monit. Assess. 172, 235-247.

Chiou, C.T., Porter, P.E., Schmedding, D.W., 1983. Partition equilibria of nonionic organic compounds between soil organic matter and water. Environ. Sci. Technol. 17(4), 227-231.

Drwal, E., Rak, A., Gregoraszczuk, E.L., 2019. Review: Polycyclic aromatic hydrocarbons (PAHs)- Action on placental function and health risks in future life of newborns. Toxicology, 411, 133-142.

Ford, D.C., Williams, P.W., 2007. Karst hydrogeology and geomorphology. Wiley, Chichester, $562 \mathrm{pp}$.

Gao, Y.Z., Xiong, W., Ling, W.T., Wang, H., Ren, L.L., Yang, Z.N., 2008. Partitioning of polycyclic aromatic hydrocarbons between plant roots and water. Plant Soil. 
311, 201-209.

514 Johnson, W.P., Amy, G., 1995. Facilited transport and enhanced desorption of polycyclic aromatic hydrocarbons by natural organic matter in aquifer sediments. Environ. Sci. Technol. 29, 807-817.

Kalf, D.F., Crommentuijn, T., van de Plassche, E.J., 1997. Environmental quality objectives for 10 polycyclic aromatic hydrocarbons (PAHs). Ecotoxicol. Environ. Saf. 36, 89-97.

Kang, H.J., Lee, S.Y., Kwon, J.H., 2016. Physico-chemical properties and toxicity of alkylated polycyclic aromatic hydrocarbons. Journal of Hazardous Materials, 312, 200-207.

Lan, J.C., Sun, Y.C., Xiang, X.Y., 2020. Ecological risk assessment of PAHs in a karst underground river system. Pol. J. Environ. Stud., 29(1), 1-11.

Lan, J.C., Sun, Y.C., Xiao, S.Z., Yuan, D.X., 2016. Polycyclic aromatic hydrocarbon contamination in a highly vulnerable underground river system in Chongqing, Southwest China. Journal of Geochemical Exploration. 168, 65-71.

Lan, J.C., Sun, Y.C., Yuan, D.C., 2018. Transport of polycyclic aromatic hydrocarbons in a highly vulnerable karst underground river system of southwest China. Environmental Science and Pollution Research, 25: 34519-34530.

Levy, W., Pandelova, M., Henkelmann, B., Bernhöft, S., Fischer, N., Antritter, F., Schramm, K-W., 2017. Persistent organic pollutants in shallow percolated water of the Alps Karst system (Zugspitze summit, Germany). Science of the Total Envrionment. 579, 1269-1281.

Lhrmann, L., Noseck, U., 1998. Model of contaminant transport in porous media in the presence of colloids applied to actinide migration in column experiments. Water Resour. Res. 34 (3), 421-426.

Liu, G., Niu, J., Guo, W., An, X., Zhao, L., 2016. Ecological and health risk-based characterization of agricultural soils contaminated with polycyclic aromatic hydrocarbons in the vicinity of a chemical plant in China. Chemosphere, 163, 461470. 
Liu, S.D., Liu, Q., Ostbye, T., Story, M., Deng, X., Chen, Y.W., Li, W.Y., Wang, H., Qiu, J.F., Zhang, J.F., 2017. Level and risk factors for urinary metabolites of polycyclic aromatic hydrocarbons in children living in Chongqing, China. Science of the Total Environment. 598, 553-561.

Marzooghi, S., Toro, D.M.D., 2017. A critical review of polycyclic aromatic hydrocarbon phototoxicity models. Environmental Toxicology and Chemistry, 9999(9999), 1-11.

McCarthy, J.F., Jimenez, B.D., 1985. Interactions between polycyclic aromatic hydrocarbons and dissolved humic material: binding and dissociation. Environ. Sci. Technol. 19, 1072-1076.

McGinley, P.M., Katz, L.E., Weber, Jr., 1996. Competitive sorption and displacement of hydrophobic organic contaminants in saturated subsurface soil systems. Water Resour. Res. 32 (12), 3571-3577.

Moeckel, C., Monteith, D.T., Llewellyn, N.R., Henrys, P.A., Pereira, M.G., 2014. Relationship between the concentrations of dissolved organic matter and polycyclic aromatic hydrocarbons in a typical U.K. upland stream. Environ. Sci. Technol. 48, 130-138.

Moon, J.W., Goltz, M.N., Ahn, K.H., Park, J.W., 2003. Dissolved organic matter effects on the performance of a barrier to polycyclic aromatic hydrocarbon transport by groundwater. Journal of Contaminant Hydrology, 60, 307-326.

Niu, S., Dong, L., Zhang, L.F., Zhu, C.F., Hai, R., Huang, Y.R., 2017. Temporal and spatial distribution, sources, and potential health risks of ambient polycyclic aromatic hydrocarbons in the Yangtze River Delta (YRD) of eastern China. Chemosphere, 172, 72-79.

Orlowski, N., Breuer, L., McDonnell, J.J., 2016. Intercomparison of soil pore water extraction methods for stable isotope analysis. Hydrol. Process. 30, 3434-3449.

Paris, A., Ledauphin, J., Poinot, P., Gaillard, J.L., 2018. Polycyclic aromatic hydrocarbons in fruits and vegetables: Origin, analysis, and occurrence. Envrionmental Pollution, 234, 96-106.

Perrette, Y., Poulenard, J., Durand, A., Quiers, M., Malet, E., Fanget, B., Naffrechoux, 
E., 2013. Atmospheric sources and soil filtering of PAH content in karst seepage waters. Organic Geochemistry, 65, 37-45.

Rav-Acha, C., Rebhun, M., 1992. Binding of organic solutes to dissolved humic substances and its effect on adsorption and transport in the aquatic environment. Water Resour. 26, 1645-1654.

Schwarz, K., Gocht, T., Grathwohl, P., 2011. Transport of polycyclic aromatic hydrocarbons in highly vulnerable karst systems. Environmental Pollution, 159,

Schwarzenbach, R.P., Westall J., 1981. Transport of nonpolar organic compounds from surface water to groundwater. Laboratory sorption studies. Environ. Sci. Technol. 15(11), 1360-1367.

Simarro, R., Gonzalez, N., Bautista, L.F., Molina, M.C., 2013. Biodegradation of highmolecualar-weight polycyclic aromatic hydrocarbons by a wood degrading consortium at low temperatures. FEMS Microbiol Ecol, 83(2), 438-449.

Sun, Y.C., Zhang, S.Y., Lan, J.C., Xie, Z.L., Pu, J.B., Yuan, D.X., Yang, H., Xing, B.S., 2019. Vertical migration from surface soils to groundwater and source appointment of polycyclic aromatic hydrocarbons in epikarst spring systems, southwest China. Chemosphere, 230, 616-627.

Sverdrup, L.E., Nielsen, T., Krogh, P.H., 2002. Soil ecotoxicity of polycyclic aromatic hydrocarbons in relation to soil sorption, lipophilicity, and water solubility. Environ. Sci. Technol. 36, 2429-2435.

van Noort, P.C.M., 2009. Estimation of amorphous organic carbon/water partition coefficients, subcooled aqueous solubilities, and n-octanol/water distribution coefficients of alkylbenzenes and polycyclic aromatic hydrocarbons. Chemosphere, 74, 1018-1023.

Wells, M., Wick, L.Y., Harms, H., 2005. Model polymer release system study of PAH bioaccessibility: the relationship between "rapid" release and bioaccessibility. Environ. Sci. Technol. 39, 1055-1063.

Xie, Z.L., 2017. Study on distribution and migration of PAHs of different forms in karst system - A case of Laolongdong river system in Chongqing (In Chinese). School 
603 Yang, L.Z., 1985. Distribution of subterranean rivers in south China. Carsologica Sinica. 3(1-2), 92-100.

605

606

607

608

609

610

611

612

613

614

615

616

617

618

619

620

621

622

623

624

625

626

627

628

629

630

631

632

633

634

635

636

637

Yang, R., Liu, Z.H., Zeng, C., Zhao, M., 2012. Response of epikarst hydrochemical changes to soil $\mathrm{CO}_{2}$ and weather conditions at Chenqi, Puding, SW China. Journal of Hydrology. 468-469, 151-158.

Yuan, D.X., 2000. Aspects on the new round land and resources survey in karst rock desertification areas of South China. Carsologica Sinica 19(2), 103-108. (in Chinese)

Zhao, X.Y., Ren, L.H., Ji, Y.Q., Yang, W., Bai, Z.P., Zhou, Z.E., Zhai, C.Z., 2014. Source apportionment of polycyclic aromatic hydrocarbons in PM10 and PM2.5 in spring in Chongqing. Research of Environmental Sciences, 2014, 27(12): 13951402.

-

(1) 


\section{Figures}

Fig. 1 Location of sampling sites in the Laolongdong underground river system, Chongqing, Southwest China.

Fig. 2 Vertical distribution of PAHs in soil profiles

Fig. 3 Vertical variation of PAHs in soil seepage water (MT refers to the annual mean concentration of PAHs in soil seepage water; MR refers to the mean concentration of PAHs in soil seepage water during the rainy season; MD refers to the mean concentration of PAHs in soil seepage water during the dry season)

Fig. 4 Relationships between $\log \mathrm{S}, \log \mathrm{C}$ and $\log \mathrm{K}_{\mathrm{ow}}$ of PAHs in soil seepage water Fig. 5 The relationship between 5-ring PAHs and DOC in soil seepage water. $\mathrm{p}$ is the significance of confidence, $r$ represents Spearman's coefficient of rank correlation. Fig. $6 \mathrm{RQ}_{\Sigma(\mathrm{NCs})}$ values of individual PAHs and contributions to ecological risk in soil and soil seepage water from different depth 


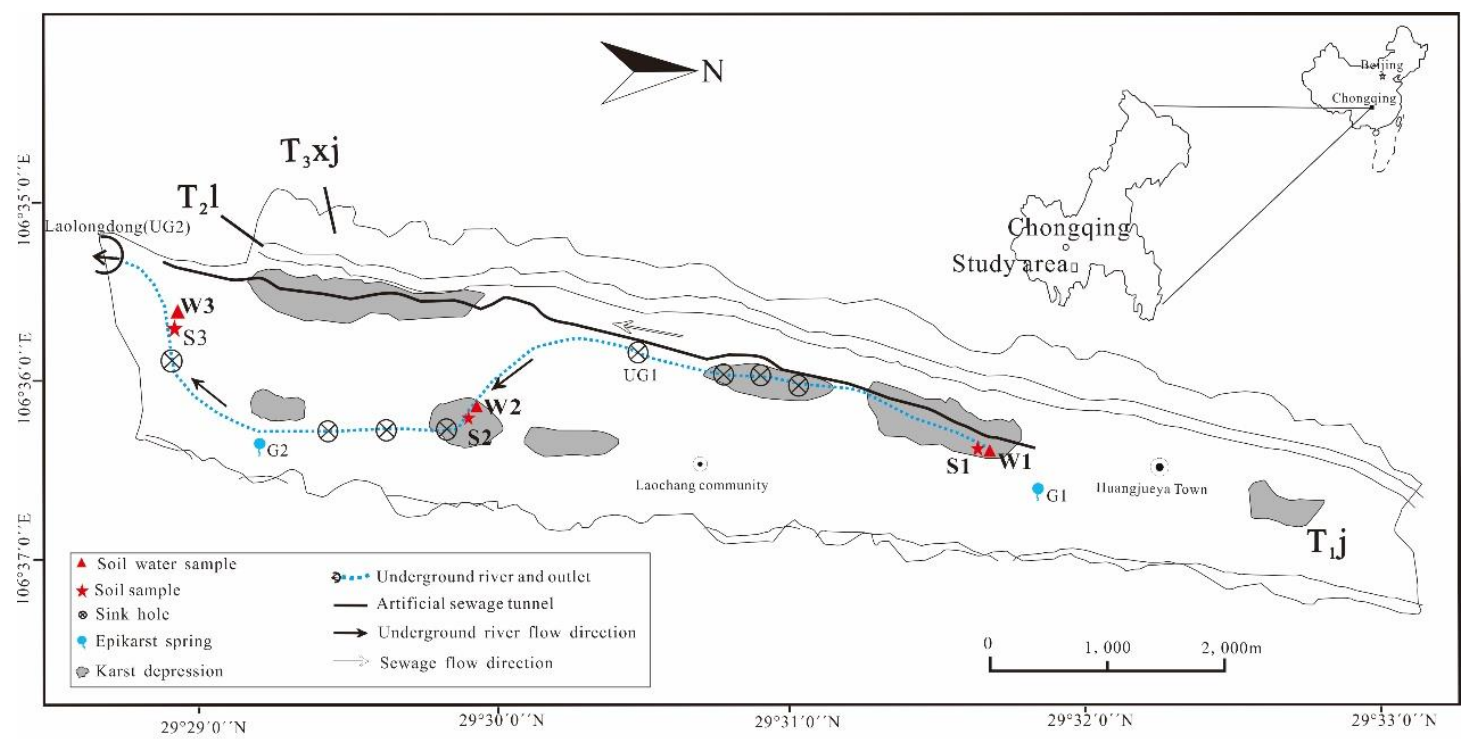

670

671

672

673

Fig. 1

674

Concentration of PAHs (ng/g)

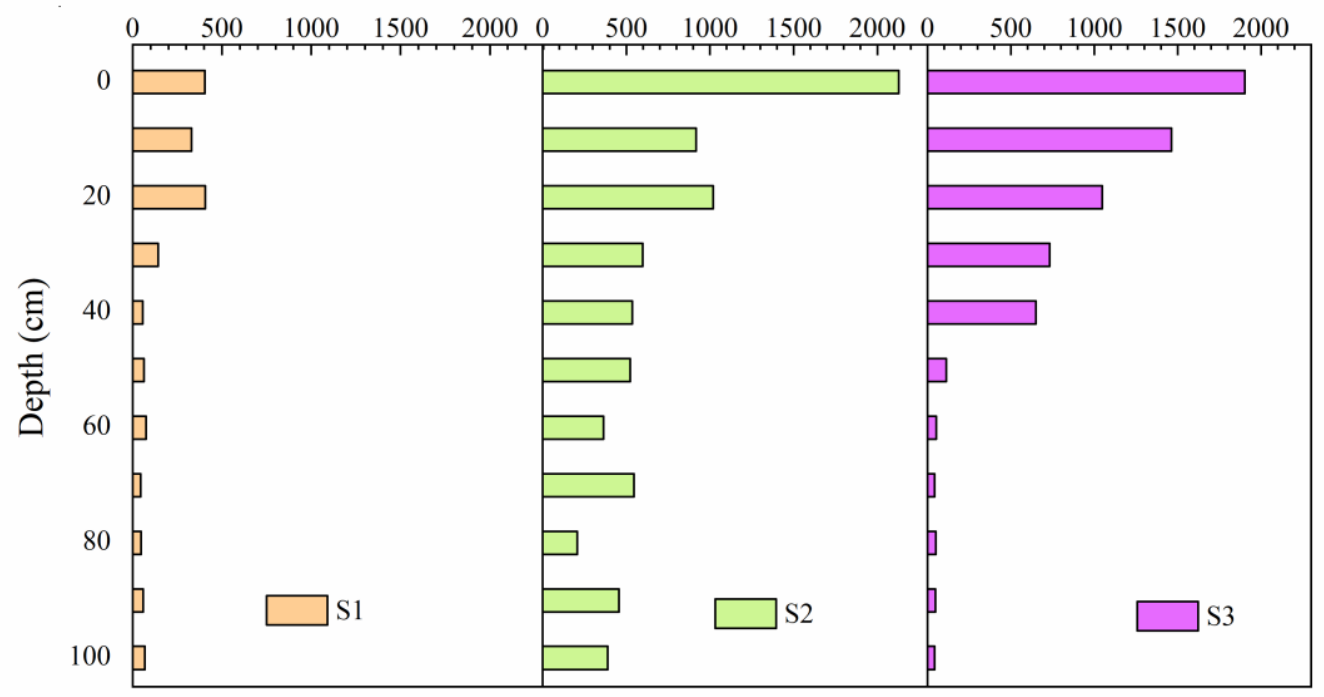

675

676

677

Fig. 2

678

679 

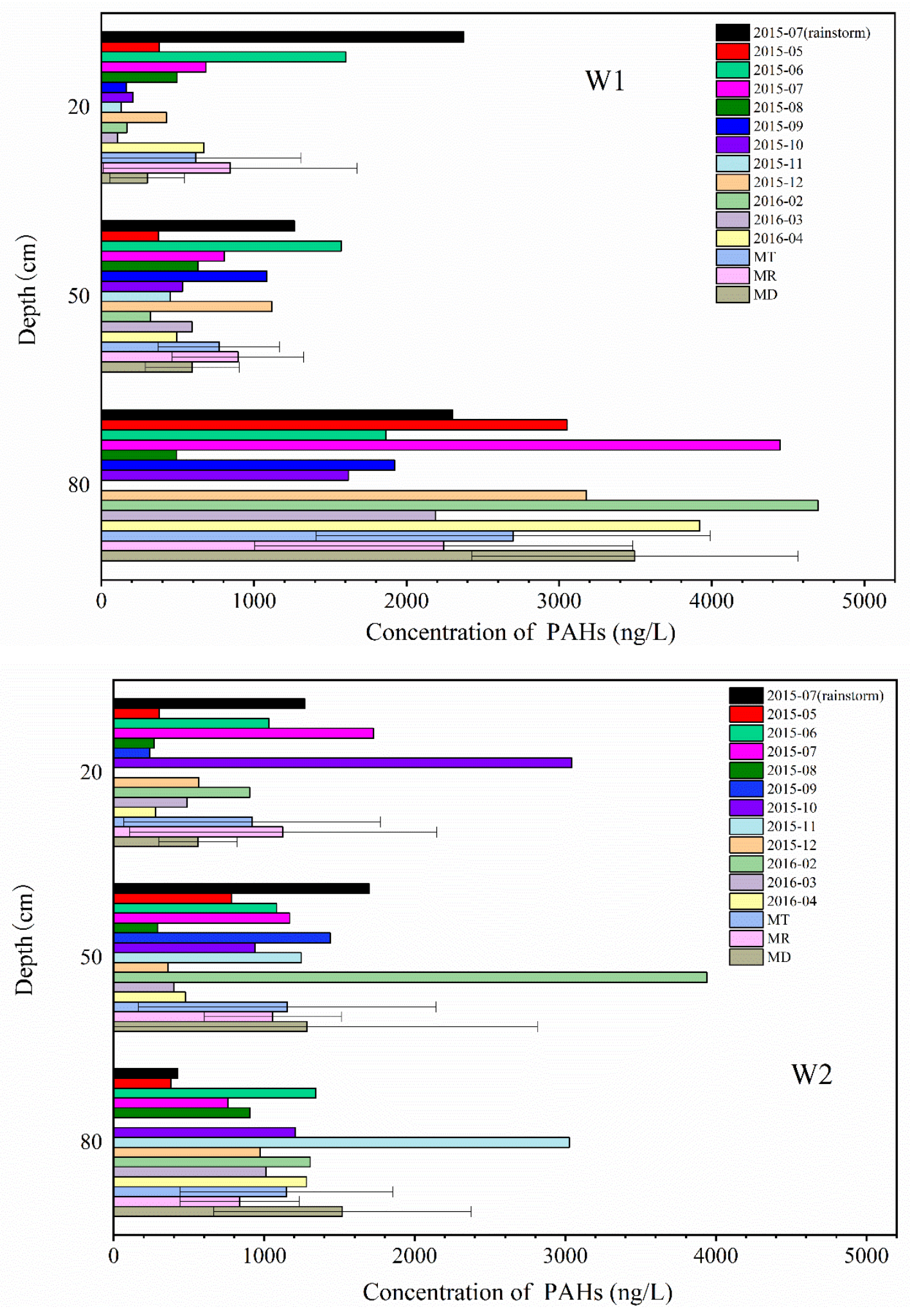

682

683

684 


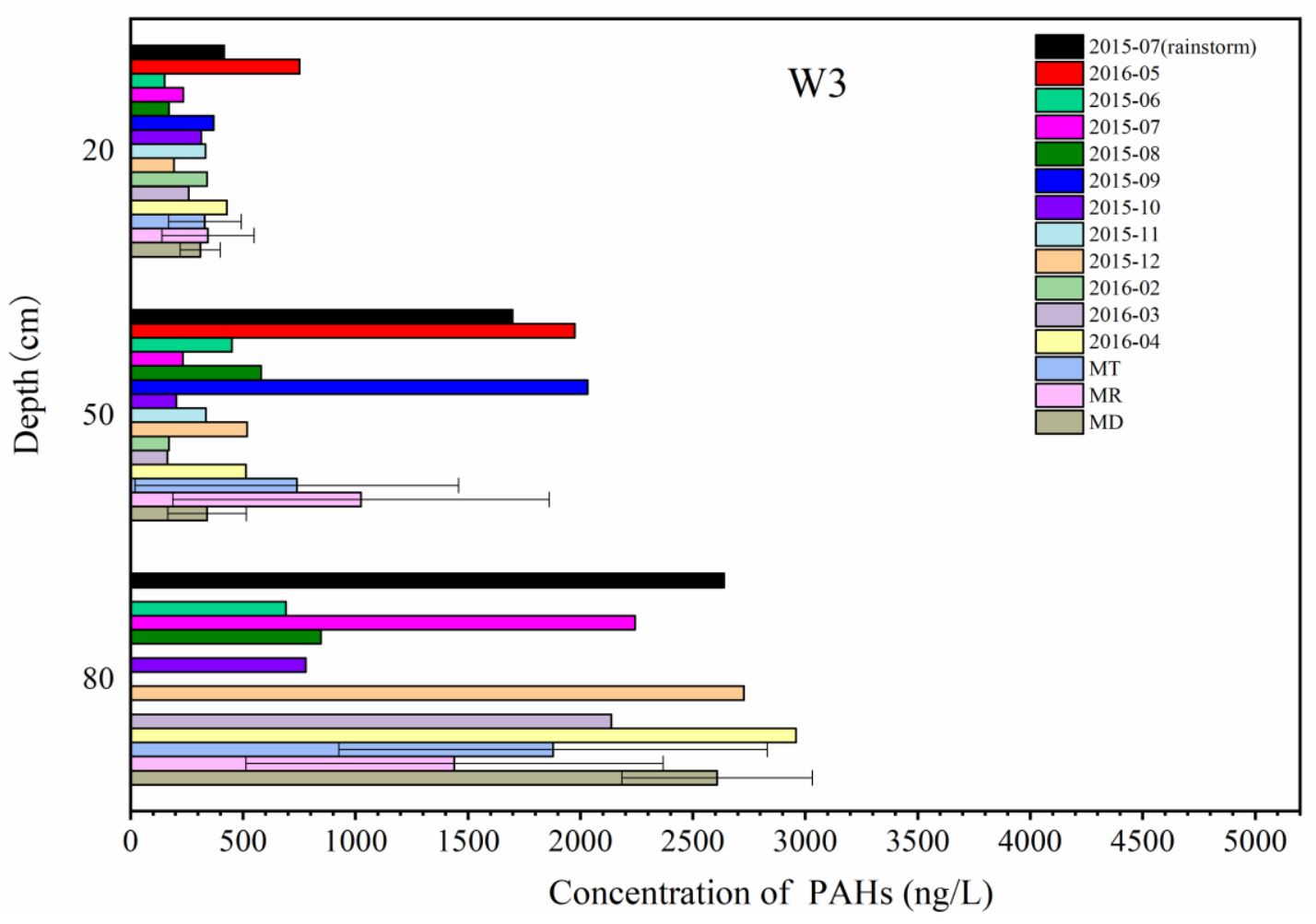

686

Fig. 3

688 (MT refers to the annual mean concentration of PAHs in soil seepage water; MR refers 689 to the mean concentration of PAHs in soil seepage water during the rainy season; MD 690 refers to the mean concentration of PAHs in soil seepage water during the dry season) 691

692

693

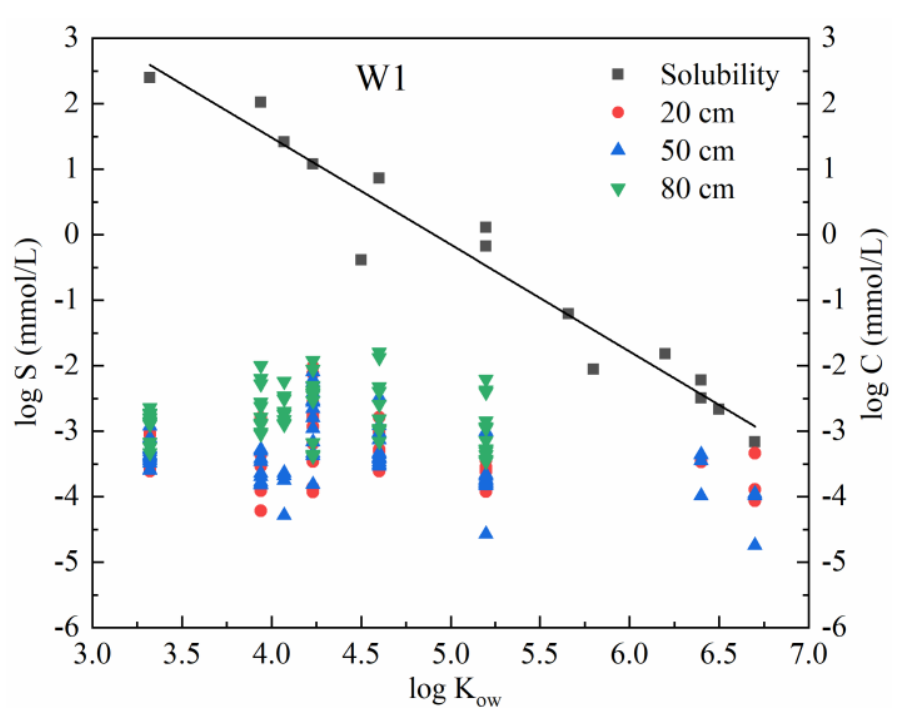




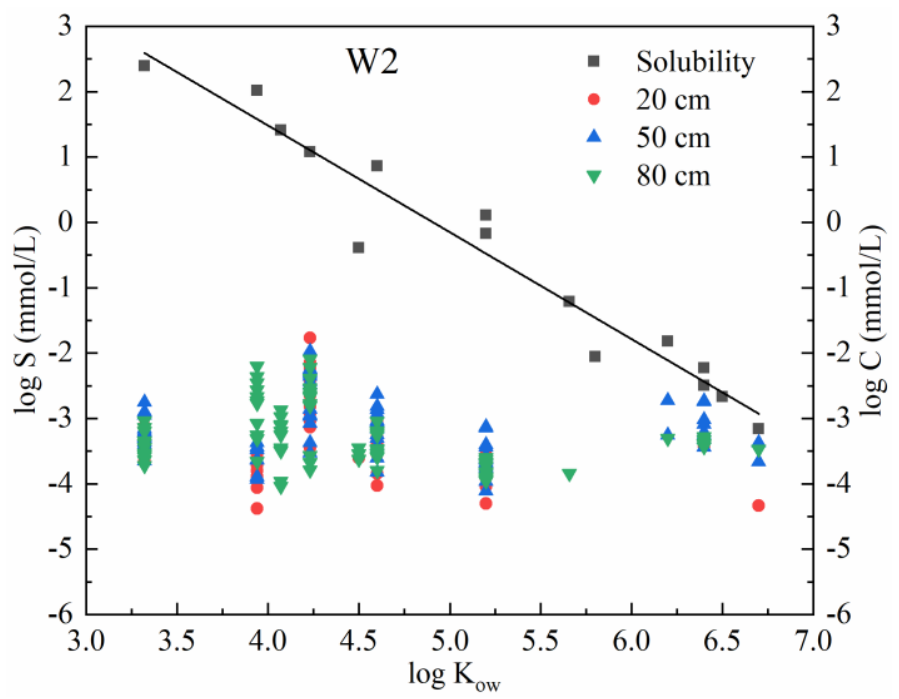

696

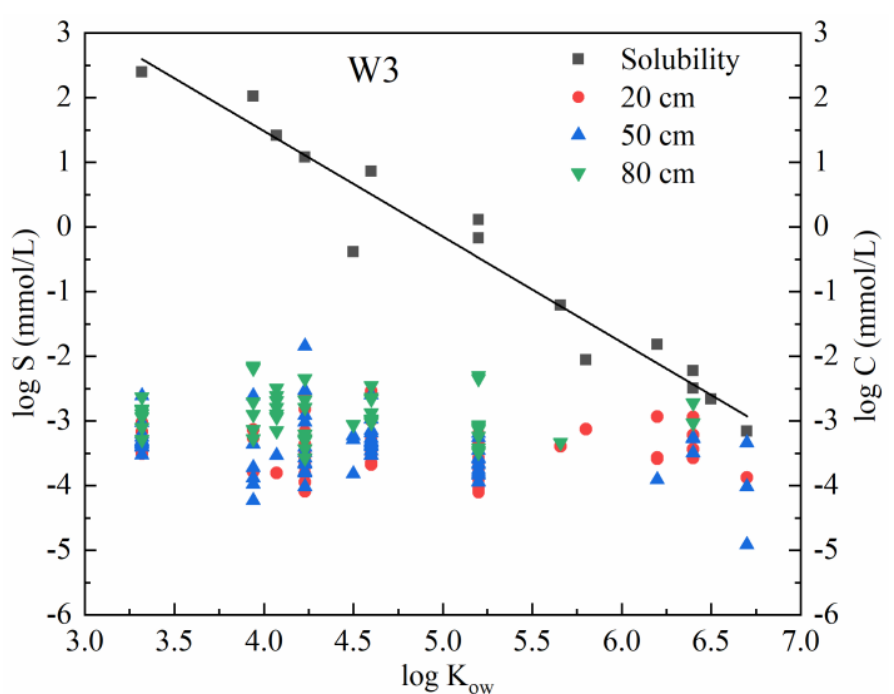

698

699

700

Fig. 4

701

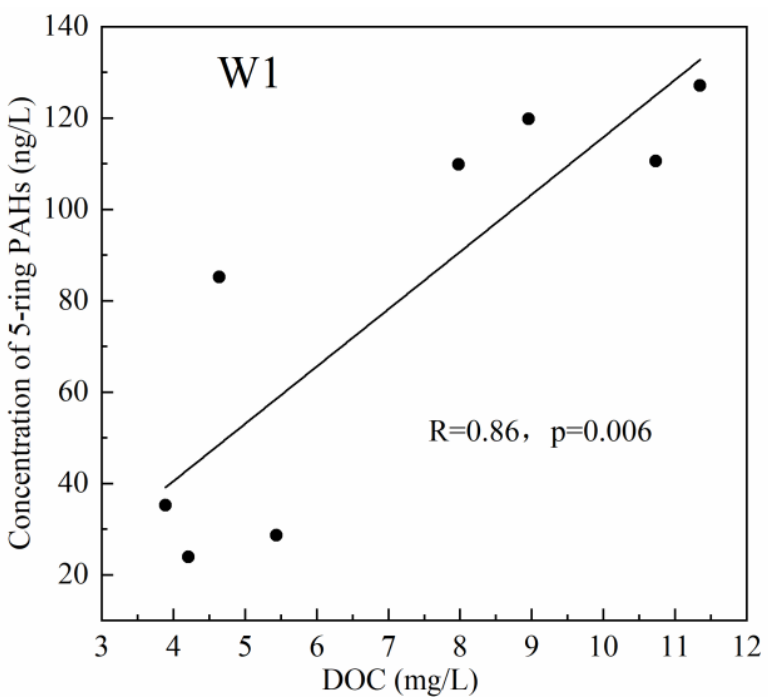



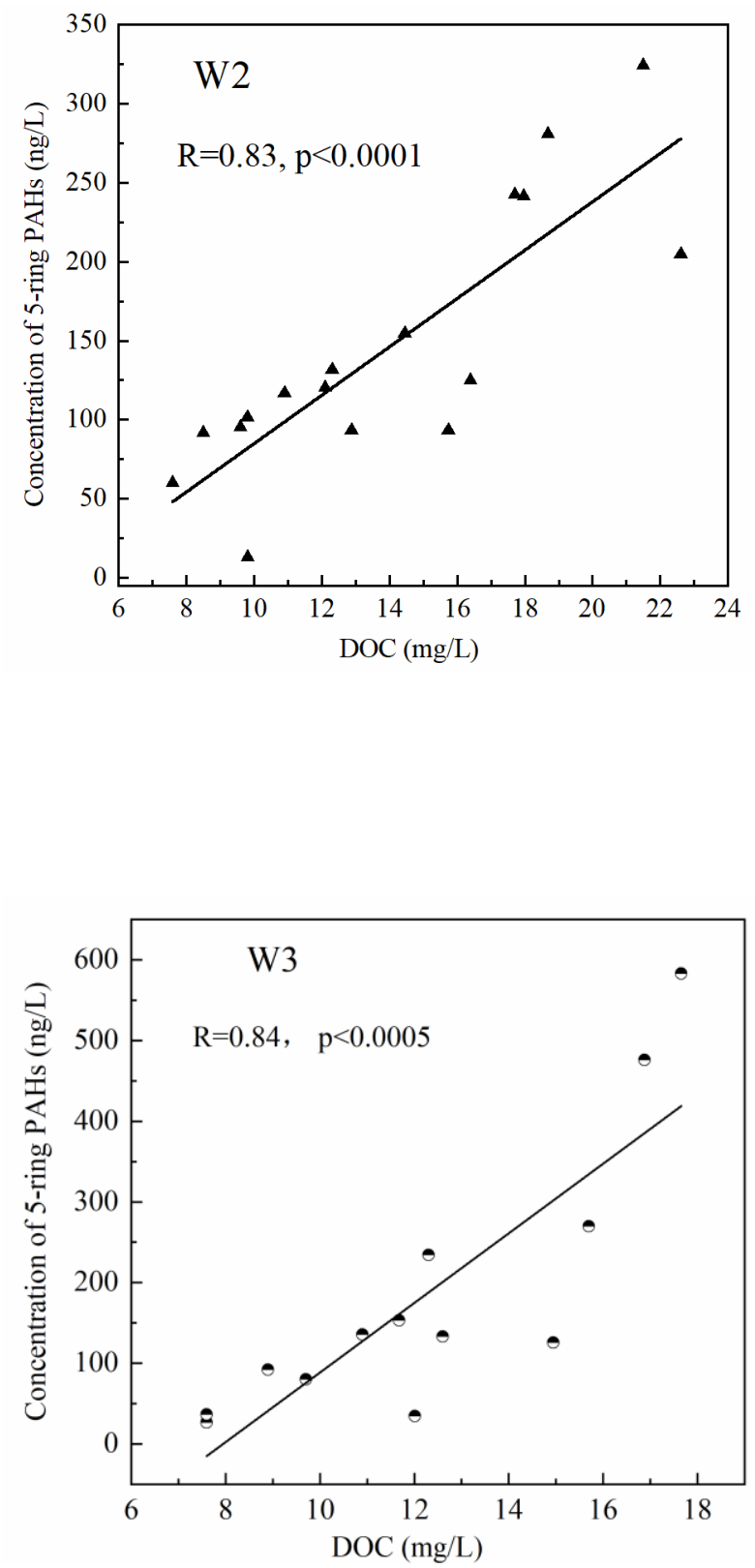

714

715

716

Fig. 5

717 

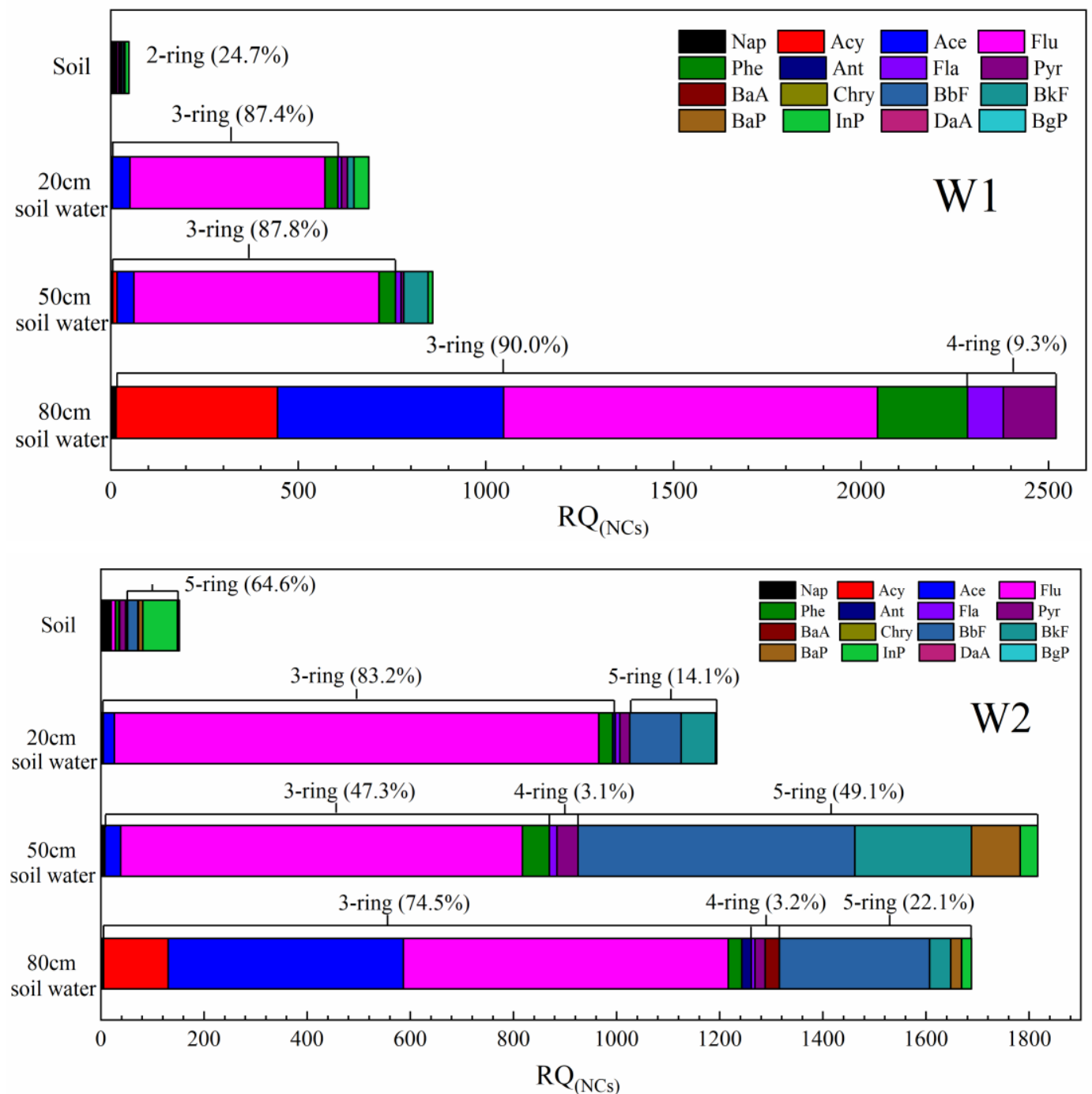

720

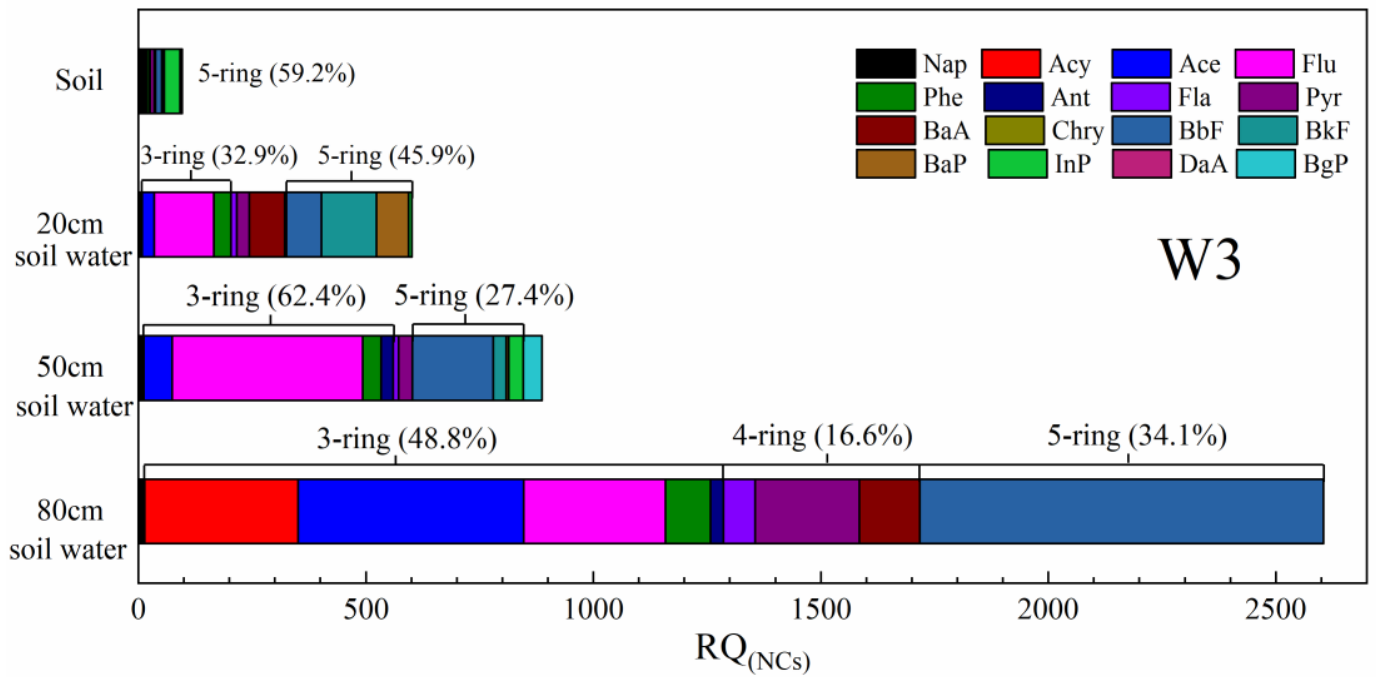

Fig. 6 